OPEN ACCESS

Edited by: Gaetano Santulli, Columbia University, United States

Reviewed by: Hack-Lyoung Kim, SMG-SNU Boramae Medical Center, South Korea Hirotsugu Tsuchimochi, National Cerebral and Cardiovascular Center, Japan

*Correspondence: Alexandra Kautzky-Willer alexandra.kautzky-willer@ meduniwien.ac.at

Specialty section: This article was submitted to Diabetes, a section of the journal Frontiers in Endocrinology

Received: 16 February 2018 Accepted: 18 April 2018 Published: 04 May 2018

Citation: Harreiter $J$ and Kautzky-Willer A (2018) Sex and Gender Differences in Prevention of Type 2 Diabetes.

Front. Endocrinol. 9:220. doi: 10.3389/fendo.2018.00220

\section{Sex and Gender Differences in Prevention of Type 2 Diabetes}

\author{
Jürgen Harreiter and Alexandra Kautzky-Willer* \\ Gender Medicine Unit, Division of Endocrinology and Metabolism, Department of Internal Medicine III, \\ Medical University of Vienna, Vienna, Austria
}

Lifestyle intervention programs are effective in the prevention of type 2 diabetes mellitus (T2DM) in high risk populations. However, most studies only give limited information about the influence of sex and/or gender effectiveness of these interventions. So far, similar outcome was reported for diabetes progression and weight loss. Nevertheless, long-term data on cardiovascular outcome are sparse but favoring women regarding allcause and cardiovascular mortality. In both men and women, sex hormone imbalances and reproductive disorders are associated with a higher risk of T2DM development. Diabetes prevention approaches are reported for polycystic ovary syndrome, gestational diabetes mellitus, and erectile dysfunction and are presented in this review. In the surgical treatment options for morbid obese patients, sex and gender differences are present. Choices and preferences of adherence to lifestyle and pharmacological interventions, expectations, treatment effects, and complications are influenced by sex or gender. In general, bariatric surgery is performed more often in women seeking medical/surgical help to lose weight. Men are older and have higher comorbidities and mortality rates and worse follow-up outcome after bariatric surgery. A more gender-sensitive clinical approach, as well as consideration of ethnicity may improve quality of life and increase health and life expectancy in men and women with a high risk for subsequent progression to T2DM.

\section{Keywords: sex, gender, type 2 diabetes, obesity, prevention, bariatric surgery, sex hormones, ethnicity}

\section{INTRODUCTION}

The number of patients affected by type 2 diabetes mellitus (T2DM) is increasing worldwide. In 2015 , around 415 million people were affected and an expected number of nearly 650 million subjects in 2040 was estimated (1). T2DM is an increasing problem with immense importance on the health care systems worldwide such as on the affected individuals. To reduce this tremendous increase successful prevention methods are necessary, which can be implemented in a population wide setting (2). These approaches could potentially reduce the number of diabetic cases in the future considerably $(3,4)$. Many trials have effectively tested different lifestyle and pharmacological intervention methods, but did not consider sex or ethnicity as a relevant factor (5). However, several aspects of sex or gender were identified as risk factors for T2DM, such as pathophysiology, onset age, detection, burden, or management of T2DM (5-7). Moreover, the diabetes risk assessment tool of the ADA guidelines includes sex-specific items and male sex is acknowledged as diabetes risk factor (8). In the same guidelines, high-risk populations for the development of T2DM, such as African American, Hispanic, Native American, Asian American and Pacific Islanders, need to be considered for early prediabetes/diabetes screening 
(8). Indeed, diabetes prevalence is lowest in the non-Hispanic white population compared to all other ethnicities (9). In Asian populations, diabetes screenings are recommended to begin at lower BMI's than in other ethnicities ( $23 \mathrm{vs} 25 \mathrm{~kg} / \mathrm{m}^{2}$ ), due to differences in body composition (higher amount of visceral fat), higher insulin resistance, and lower second phase insulin secretion (10). Men are marginally higher affected by diabetes all over the world; they are diagnosed at younger age and at lower levels of overweight/obesity.

In weight loss studies, the majority of participants are female. Women might be more concerned by increased or increasing weight and show greater weight control involvement and thus seek medical help for weight loss therapy/surgery earlier $(11,12)$. Greatest effectiveness was seen in morbidly obese patients following bariatric surgery - usually with high female proportionleading to impressive weight loss and a relative risk reduction of the diabetes incidence of up to $84 \%(13,14)$. Lifestyle interventions effectively reduced diabetes risk by almost $60 \%$ (13). At present, there is no physiological explanation for major sex differences with regards to weight loss (15), but some trials indicate that women lose less weight than males including the more harmful visceral fat mass (15). Interestingly, women with T2DM, but not men, have a different perception of their body image compared to healthy women. They have significantly higher BMIs, at the same body image figure, than women without T2DM (16).

Although the sex of a patient has multiple effects on various aspects in T2DM management, these aspects however currently have no impact on clinical decisions. Therefore, this review briefly addresses and summarizes the important issues of sex and gender differences as well as ethnical aspects in the prevention of T2DM.

\section{METHODS}

A critical review of available peer-reviewed literature in medical databases was conducted. The search terms included the terms prevention, preventive measures, intervention, physical activity, healthy diet, T2DM, sex and/or gender, male, female, obesity, bariatric/metabolic surgery, polycystic ovary syndrome (PCOS), erectile dysfunction (ED), gestational diabetes mellitus (GDM), ethnicity, and race. Medical Subject Heading (MEsH) search terms were used if available and search terms were connected with Boolean terms. Only articles reporting human data and not older than 15 years were included. Older material was considered if highly relevant for this review or general understanding. Relevant literature was carefully examined and an additional hand search was performed to identify further relevant literature from the reference lists. A narrative synthesis approach describing results descriptively and not systematically was chosen in view of heterogeneous and limited information material.

Sex differences describe biological differences between women and men. Differences in sex chromosomes, sex-specific gene expression of autosomes, sex hormones, and their influence on organ systems are responsible for these differences between men and women (6). Gender differences are a result of sociocultural processes. Those processes specifically relevant for gender differences comprise differences in behavior, environmental exposition to specific influences, nutrition, life style and stress or different attitudes toward treatment and prevention (6). An accurate distinction between "sex" and "gender" effects is often not possible because these complex processes are interrelated and interact with each other during lifetime, including epigenetic mechanisms. Therefore, in this review, sex will be used to indicate primarily biological differences and gender to describe predominant psychosocial influences. However, the manifold interactions between biological, societal, and cultural influences in the risk and potential prevention of T2DM have to be kept in mind.

\section{INTERVENTIONS}

\section{Lifestyle Changes}

Few prevention trials and systematic reviews provide information on potential sex or gender differences in diabetes prevention. In men and women with pre-diabetes, a meta-analysis of diabetes-prevention trials showed equal effectiveness in diabetes risk reduction and weight loss in both sexes receiving lifestyle interventions, up to 3 years after intervention (5) (Figure 1). A nearly $40 \%$ risk reduction was observed after 1 and 3 years accompanied by a significant weight loss of nearly $-2.5 \mathrm{~kg}$ after 3 years. Therefore, promotion of healthy behavior is important with special attention to those aspects of lifestyle changes that are more often neglected in one sex, which are healthy nutrition in men and physical activity in women $(6,11,17,18)$. Moreover, no sex differences in the association of oral glucose-lowering drugs

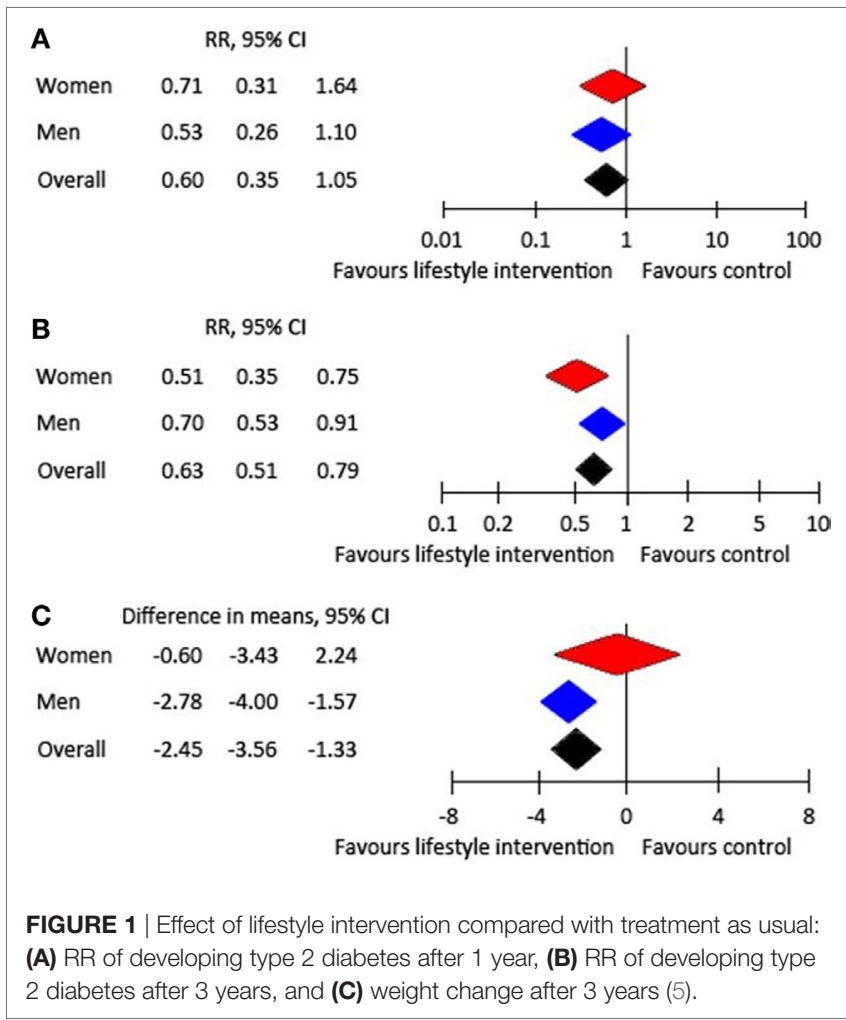


with the reduction of T2DM were found due to limited data available (5). Unfortunately, information about relevant differences between men and women in adverse events was insufficient.

Interestingly, a recently published Indian study was able to demonstrate a stronger relative diabetes risk reduction in male and obese participants older than 50 years, who received a stepwise intervention approach initially starting with lifestyle changes and then followed by metformin prescription, if required (19). Men had a significant reduction of $37 \%$, whereas women had a non-significant reduction in diabetes incidence of $24 \%$. No significant differences between sexes were found, but men seem to achieve their physical activity goals after 6 months and 1 year significantly more often than women. Initially, women indicated to encounter more barriers to participate in the study (20). According to the authors, the latter had influence on recruitment outcomes and lifestyle changes. Overall, more than $63 \%$ of the study population was male.

In the Diabetes Prevention Program (DPP), intensive lifestyle modification reduced the diabetes risk in the intervention group (21). Although, women achieved significantly more lifestyle modification goals than men, the diabetes incidence was comparable. Baseline risk factor analysis revealed differences with higher age, waist circumference, fasting plasma glucose, caloric intake, blood pressure, and lower HDL cholesterol levels in men and higher $\mathrm{BMI}$ and physical inactivity in women. In patients with weight loss below $3 \%$, no sex differences were observed after 1 year. Weight loss from 3 to $7 \%$ led to lower $2 \mathrm{~h}$ glucose and insulin levels, as well as improved insulin resistance in men compared to womenabove $7 \%$ additionally ameliorated triglyceride and $\mathrm{HbAlc}$ levels were reported, which was more pronounced in men (21).

Recently, a study examined activity and sedentary time in participants of the Diabetes Prevention Program Outcome Study (DPPOS) followed-up 10 years after the lifestyle modifications in the original trial. Higher moderate to vigorous physical activity (MVPA) was assessed by accelerometers in all DPPOS subgroups with T2DM or IGT in both sexes, compared to adults participating in the National Health and Nutrition Examination Survey (NHANES) (22). This was especially pronounced between 60 and 69 years in men and women with T2DM and men with IGT. In general, MVPA was significantly higher in men of the DPPOS follow-up compared to women and women more often had low physical activity levels. Interestingly, no differences in sedentary behavior were found between sexes. Physical activity decreased significantly with increasing age. Nevertheless, the evaluation of longitudinal questionnaire data found significantly increased activity in all groups in the DPPOS compared to baseline data of the original DPP trial, which demonstrates lasting lifestyle changes in men and women of all age groups, following effective lifestyle intervention programs and is in contrast to reports of stagnant or decreasing physical activity levels (22-24).

In women participating in the lifestyle intervention group of the Da Qing Study, a potential benefit was shown in cardiovascular and all-cause mortality (25). After 23 years of followup, the female risk of cardiovascular mortality and all-cause mortality was reduced by more than 70 and 50\%, respectively, in the intervention group compared to usual care, whereas in men, no intervention effect was found. Part of this might be explained by a high prevalence of smoking in men compared to low prevalence in women. However, this is only speculative and was not extensively discussed in the original paper. Furthermore, low participant numbers were followed up after this long-time period and different lifestyle behavior, cultural and ethnical differences need to be taken into account before a generalization of these results is possible at all. To further clarify potential sex or gender differences as well the influence of ethnicity and other sociocultural aspects in mortality after lifestyle intervention more evidence from long-term follow-up prevention trials is necessary.

As described above, ethnical differences next to sex and gender differences need to be considered in weight loss and lifestyle intervention programs. A secondary analysis of the DPP demonstrated significantly lower success in weight loss in the lifestyle intervention arm in black women compared to all other ethnical groups (26).

Latinos appeared to benefit less from the NDPP with lower weight loss most likely because of a $50 \%$ lower attendance rate of the programm sessions (27). In addition this ethnic group was younger, had a lower income and comprised an even higher percentage of women compared to the Non-Hispanic white participants (27). Barriers to attendance among underserved patients might be the main reasons but were not further investigated.

Sex differences were also found in the Prevention of Diabetes and Obesity in South Asians (PODOSA) study between Pakistani and Indian male and female migrants in a secondary analysis of this weight loss intervention study. Asian men in the intervention arm (culturally adapted diet and physical activity) had higher weight loss compared to Asian women (28). This finding was corroborated by a study investigating lifestyle effects on Asian Indian migrants older than 50 years. Asian Indian men had significant reductions in body weight, body fat, waist circumference, and abdominal fat, whereas in women, these changes were not observed after 5 months of intervention (29).

Culturally tailored DPPs were shown to be effective in another recent randomized control trial, including Asian Indians (Gujarati) living in an urban community (30). After a 12-week group-based lifestyle intervention program aiming for weight loss and increased physical activity, the intervention group had significantly lower weight, $\mathrm{HbA1c}$, and waist circumference as well as significantly increased physical activity compared to the control group. Sex differences were not analyzed. A systematic review identified 34 culturally adapted diabetes prevention intervention trials specific for minority populations of which 25 trials significantly improved $\mathrm{HbAlc}$, fasting glucose, or weight loss (31). A framework of four key domains including Facilitating Interventions through Language, Location, and Message (FiLLM) was developed to assess overall effectiveness of these. In this context, six mediators were identified, which are relevant for successful lifestyle behavioral change, which are gender, generation, geography, genes, religion, and gaps in knowledge and economic resources (32). All these studies demonstrate the necessity for awareness of the high risk among minority groups and for evaluation of culturally tailored interventions based on sociocultural and environmental differences in future DPPs. Analysis by sex is often missing in studies in minorities and should therefore also be included in future study designs. 
As discussed in a recent article, lifestyle intervention compared to no intervention is a cost-effective strategy (33). The potential cost effectiveness of hypothetical prevention methods in men and women at all ages compared to no intervention was reported. A Swedish setting was used in the analysis, assuming a hypothetical intervention-comparable to those used in the Finish Diabetes Prevention Study-including male and female sex, different ages, and several states of impaired glucose tolerance (33). A high probability of cost effectiveness was shown, with an assumed threshold of 50,000 Euros per QALY gained. The authors concluded that a DPS-like intervention is highly likely to be effective in reducing risk of T2DM progression and thus will be cost-effective in both sexes, among different glucose tolerance stages and across all age categories.

Key points: data regarding sex and gender differences of diabetes prevention trials are limited. Comparable improvements in glycemic control or weight loss up to 3 years after intervention were reported in men and women. However, various sex/gender as well as ethnical differences regarding effectiveness, lifestyle goal achievement, or barriers to participate in a study were indicated. Lower cardiovascular mortality in women participating in the lifestyle arm and no effect in men was observed compared to controls (Table 1).

\section{Weight Management Programs}

A systematic review of RCTs with long-term weight management interventions found that men are less likely to participate in such interventions, representing about one-third of the total study population (34). Nonetheless, attrition rates are much higher in women included in a trial and thus men are more likely to complete a study. In this analysis, including more than 8,400 male and female participants of 13 RCTs, no significant differences in weight loss or percentage loss between men and women were observed; however, strategies how to reduce weight effectively may differ between sexes. Men may have higher benefit of a lowfat diet and defined physical activity interventions with individual and tailored support. In contrast pharmacological approaches, as shown for Orlistat, are more successful in reducing and maintaining weight in women. Social support from a partner is reported to be more helpful in men. The authors conclude that interventions need to be developed, which attract men and make them feel convenient, which is probably best delivered by gender-sensitized interventions $(11,34)$.

An Internet delivered weight-loss intervention found significantly higher weight reductions in non-Hispanic white women compared with African American women, which was explained

TABLE 1 | Summary of sex and gender differences in diabetes prevention.

\begin{tabular}{|c|c|c|c|c|}
\hline & Men & Women & Notes & Reference \\
\hline \multirow[t]{4}{*}{ Lifestyle changes } & + & + & $\begin{array}{l}\text { RCTs: after } 3 \text { years equal effectiveness in both sexes: } 40 \% \text { risk reduction and significant weight loss; } \\
\text { no sex differences in the association of oral glucose-lowering drugs with T2DM risk reduction }\end{array}$ & (5) \\
\hline & + & $(+)$ & Indian RCT: stronger diabetes risk reduction in elderly obese men, more barriers to participate in women & $(19,20)$ \\
\hline & + & $(+)$ & $\begin{array}{l}\text { DPP and DPPOS: greater improvement in glucose tolerance, insulin resistance, HbA1c, and triglycerides in men. } \\
\text { Higher MVPA in men, more often low physical activity in women. Black women lower success in weight loss }\end{array}$ & $(21,22,26)$ \\
\hline & 0 & + & DAQING: lower cardiovascular mortality and all-cause mortality in women in long-term follow-up & (25) \\
\hline \multirow[t]{2}{*}{$\begin{array}{l}\text { Weight management } \\
\text { programs }\end{array}$} & + & $(+)$ & $\begin{array}{l}\text { Men are more successful in reducing and maintaining weight than women in the majority of studies. } \\
\text { Race-sex subgroup analysis: black and white men more success in weight loss than women }\end{array}$ & $(11,34,37)$ \\
\hline & $(+)$ & + & Women are more successful in reducing and maintaining weight with pharmacological approaches (Orlistat) & $(11,34)$ \\
\hline \multirow[t]{2}{*}{ Exercise Program } & + & + & Both sexes prefer to exercise with members of their own sex relative to exercising in gender-mixed groups & $(42)$ \\
\hline & + & + & $\begin{array}{l}\text { Sex-specific team-sports-based intervention programs in men and women show higher effectiveness, } \\
\text { weight loss, amelioration of blood pressure, and quality of life compared to controls }\end{array}$ & (51) \\
\hline \multirow[t]{3}{*}{ Bariatric Surgery } & + & ++ & $\begin{array}{l}\text { Strong diabetes risk reduction: higher frequency of bariatric surgery in women due to differences regarding } \\
\text { expectations and willingness, related to body image and psychosocial factors in women or obesity-related } \\
\text { health concerns and morbidities in men }\end{array}$ & $(14,59,63)$ \\
\hline & - & - & Higher complication and mortality rates following surgery in men, higher rates of revision procedures in women & $(60,61,65)$ \\
\hline & + & ++ & Gastric banding may be less efficient in males than females & (69) \\
\hline Hormonal imbalance & - & - & Increased diabetes risk in men with hypogonadism or women with hyperandrogenemia & (78) \\
\hline Erectile dysfunction & + & n.a. & $\begin{array}{l}\text { Positive effect of lifestyle intervention on erectile function, weight loss, and physical activity; reduction in all-cause } \\
\text { mortality, trend for reduction of major adverse cardiovascular events or incident diabetes }\end{array}$ & $(91,98)$ \\
\hline \multirow{2}{*}{$\begin{array}{l}\text { Hormone replacement } \\
\text { therapy }\end{array}$} & + & n.a. & TRT: improvement in anthropometrics, glucose tolerance, lipids, blood pressure, and sexual function and desire & (89) \\
\hline & n.a. & + & $\begin{array}{l}\text { HRT after menopause reduces the risk of T2DM and improves glycemic control. HRT within } 10 \text { years after } \\
\text { menopause and below } 60 \text { years of age is effective in preventing development of T2DM and cardiovascular } \\
\text { disease }\end{array}$ & $(118)$ \\
\hline \multirow[t]{3}{*}{ PCOS } & n.a. & + & Lifestyle intervention and metformin effectively reduce weight and subcutaneous fat & $(109)$ \\
\hline & n.a. & + & Myoinositol supplementation - lower insulin resistance and a trend for reduction of androgens & $(110)$ \\
\hline & n.a. & + & DPP4 inhibitors - improvements in beta cell function and insulin resistance with lower conversion rates to T2DM & $(111)$ \\
\hline
\end{tabular}

0, no effect; + positive effect; -, negative effec; n.a., non appropriate; RCT, randomized controlled trial; DPP, Diabetes Prevention Program; DPPOS, Diabetes Prevention Study, Diabetes Prevention Study Follow Up; MVPA, moderate to vigorous physical activity; ED, erectile dysfunction; TRT, testosterone replacement therapy; HRT, hormone replacement therapy; PCOS, polycystic ovary syndrome; DPP4, dipeptidylpeptidase 4. 
by higher website engagement and changes in eating behavior in non-Hispanic white women (35). Interestingly, contrary to African American women maintaining lifetime normal weight, those who were overweight before in their lives were more insulin sensitive and thus might be predisposed for obesity and fat accumulation (36). An ethnicity specific effect of higher insulin responsiveness was identified in African American women compared with European American women, which might be further relevant for obesity predisposition.

A study trying to identify predictors of successful weight loss and maintenance (WLM) in race-sex subgroups (black or white men and women) found within race, men losing significantly more weight than women, but no differences in weight loss within sex group between races (37). Predictors beyond initial weight loss identified in most subgroups were healthy nutrition at entry and improvements in diet throughout the study period. However, black men showed no potentially modifiable variables except initial weight loss. In white men, only MVPA additionally predicted long-term weight loss. Further important factors for successful weight loss identified were social support and social pressure for weight loss activities, which were higher in white compared to black women (38). Social support seems to be an essential motivator, especially in black women, to participate successfully and engage more intensively in weight loss activities (39). In a study investigating the effectiveness of a communitybased weight loss program with implementation of two different strategies over a duration of 2 years in an obese, low-income Latino population, women had significantly lower weight loss than men (40). However, sustained weight could not be achieved in either sex.

Key points: men are less likely to participate in weight management interventions than women. Weight loss is more successful in black and white men compared to women. Pharmacological approaches are more successful in reducing weight in women. Social support from a partner is more helpful in men (Table 1).

\section{Exercise/Sports Programs}

In the analysis of the total study population of the Henry Ford Exercise Testing (FIT) project, including men and women, a reduction of risk for incident T2DM by $54 \%$ was found in those participants with at least 12 metabolic equivalents compared to those subjects achieving less than 6 METs regardless of sex (41).

Based on recent evidence both sexes prefer to exercise with members of their own sex relative to exercising in gender-mixed groups (42). These preferences for gender-segregated physical activity groups are even stronger in overweight subjects. This was corroborated by another study, which reported similar observations in obese adults (43). Additionally, obese participants indicated to prefer activities with people of similar age. So far this was only reported in observational studies and needs further proof in randomized controlled trials. The Canadian GOAL study will try to investigate age- and gender influences on physical activity adherence behaviors in three different age and sex groups: one group consists of participants of similar age and same sex, the second group includes same sex but different ages and the third group is a group of patients of different sex and ages (44). Overweight and obese participants of physical activity classes might feel embarrassed or stigmatized, emotionally insecure or unaccepted and thus seek solidarity and empathy in same age same sex physical activity groups (43). Therefore, same sex-groupbased exercise programs may be more successful, probably due to better motivation, adherence behavior, and social congruence. Shared social identity, which can be described as the identification of a person with a group with similar characteristics (e.g., sex, age, physical appearance, ethnicity, cultural background) and the motivation to get involved, integrate and become a member of this group, seems a major motivational factor for participants of group-based exercise programs to show higher adherence and thus potential better outcome than members feeling different from the group $(45,46)$. This strategy seems to provide a dynamic body for the development of new prevention programs; however, the social identity approach is currently under-investigated and further evidence is necessary to prove effectiveness and feasibility of such interventions (45).

In fact, a gender-sensitized weight loss and healthy living program based on a social identity approach for overweight and obese men delivered by football clubs was very successful in Scotland (47). In this pragmatic RCT, the intervention group lost almost $5 \mathrm{~kg}$ more weight than the comparison group within 1 year. In the intervention group, blood pressure and percent fat content decreased significantly and diet and quality of life improved. Such male-specific initiatives may be very promising in tackling male obesity, as men are under-represented in common gender-integrated weight loss programs. Currently, more gender-sensitized studies are ongoing, which are evaluating the effectiveness and cost-effectiveness of an evidence and theory-based, gender-sensitized, multinational health program attracting men through the loyalty to their football clubs in four European countries (48). Another program tried to improve physical activity and healthy eating choices, leading to subsequent weight loss and other health outcomes through a lifestyle program over 52 weeks (12 weeks active phase and 40-week minimal support phase) for overweight or obese male hockey fans with BMI above $28 \mathrm{~kg} / \mathrm{m}^{2}$ in Ontario, Canada $(49,50)$. After 12 weeks, the intervention group had $3.6 \mathrm{~kg}$ higher weight loss compared to control group, which was preserved until the end of the study after 12 months. Moreover, increases in physical activity, self-rated health, a healthier diet, and improvements in several other clinical parameters were observed. A further gender-sensitized hockey intervention program based in Canada called HATTRICK, which is currently ongoing, is also focusing on improving physical activity and healthy eating in inactive and overweight men and will report further evidence on gendersensitized lifestyle intervention provided to inactive men through team-sports-based intervention programs (51). These studies are aimed to address overweight or obese subjects and not directly to prevent T2DM progression, although excess weight is a substantial risk factor for insulin resistance and diabetes progression. So far, these programs are undoubtedly wonderful examples how to promote physical activity and lifestyle changes in highly inactive men at risk.

A recent Swedish cohort study with military conscripts reported that a combination of low aerobic capacity and low muscle strength at the age of 18 years was associated with a threefold higher risk of 
T2DM in adulthood, which was independent of BMI, family history, or socioeconomic factors (52). This study demonstrates, that early prevention starting at young age, which improves aerobic and muscular fitness, was able to reduce T2DM in adulthood in male subjects independent of body weight. However, the authors concluded that more research with longitudinal fitness measurements is needed to find out important windows of susceptibility (52). This is corroborated by another huge nationwide cohort study from Israel, which investigated the association of childhood obesity at the age of 17 years, with diabetes mortality followed over a median time period of 18.4 years. Increased diabetes mortality starting already at normal weight from the 25th-49th BMI percentile and an 8-and 17-fold higher risk for diabetes mortality in overweight and obese subjects, respectively, after adjustment for sex, age, birth year, height, and sociodemographic variables was found (53). Mortality rates increased tremendously with increasing age. Further risk factors identified were lower body height, low socioeconomic status, or educational status, North African and former Union of Soviet Socialist Republics origin, as well as male sex.

Gender-sensitized intervention programs were also studied in women and demonstrated promising results in the reduction of various risk factors of cardiovascular and metabolic disease (54), as well as bone metabolism and cancer risk. A recently performed Scandinavian study was able to demonstrate the effectiveness of soccer training in middle-aged women with mild hypertensive disorder and reported an amelioration of blood pressure, plasma lipid levels, bone density, total body fat mass and better performances in endurance and sprint compared with control (55). This study, among others, clearly shows that team-sports-based interventions are also an effective tool to improve cardiovascular and metabolic health in untrained middle-aged women $(54,55)$. Similar beneficial effects of soccer training in women on cardiometabolic parameters were reported earlier by the same group of investigators (56). A further study compared soccer training with different intensities of swim training and control in middle-aged women and found higher bone turnover markers after 15 weeks of soccer training, whereas no changes were found in swim groups and control (57). High intensity intermittent training was reported to be associated with improvements in metabolic parameters and glycemic control and team-sports-based interventions incorporate a blend of various training components, as endurance, highintensity exercise and resistance training (54). Therefore, such trainings and broad-spectrum health improvements may also be applicable in women with prediabetes or high risk to develop T2DM. However, studies to investigate team-sports-based interventions in the prevention of T2DM in women are missing. Studies including women with T2DM applying team-based soccer and dietary interventions for 12 weeks demonstrated increased insulin sensitivity and ameliorated lipid profiles, as well as higher maximal oxygen uptake in women with T2DM in the soccer and dietary intervention groups compared with dietary group alone (58). Team-based soccer activities are popular in Scandinavian countries and give evidence that a social identity approach is successful to motivate inactive women for participation in team-based soccer training as shown in a
Danish initiative called "Football Fitness" and a similar project on Faroe Islands (54). They truly might have the potential to reduce T2DM progression at a nationwide scale in women (and men) at risk, although this needs further proof.

Key points: physical exercise reduces the risk for incident T2DM in men and women. Sports-clubs-based, gender-sensitized lifestyle programs for men and women demonstrated significant weight reduction and improvement in cardiometabolic parameters. Socially and culturally tailored intervention programs are able to increase adherence and motivation to participate and thus have the potential to increase the outcome of such interventions (Table 1).

\section{Bariatric Surgery}

In morbidly obese patients, lifestyle intervention or pharmacological intervention do often not result in significant and sustained weight loss. Thus, surgical options are used, which have demonstrated a significant potential in reducing weight. In literature, several sex and gender differences are reported regarding expectations and willingness toward surgical treatment, complication rate and weight reduction.

A systematic review showed that females have greater willingness to undergo bariatric surgery (14). Female patients have higher expectations regarding weight loss and reasons for undergoing surgery are strongly related to body image and psychosocial factors. Males report obesity-related health concerns like diabetes, hypertension, or sleep apnea, as crucial for their decision (59).

Indeed, male patients suffer more comorbidities before a surgical intervention and have higher complication and mortality rates following surgery $(60,61)$. Also, other studies corroborate these differences in clinical aspects between men and women before laparoscopic RYGB. In a large observational study including more than 83,000 patients (62) with the majority being female, men were older and had significantly higher rates of metabolic impairment (diabetes, gout, dyslipidemia), abdominal hernia, liver disease, alcohol and tobacco abuse and cardiopulmonary disease except asthma, which was more common in women, next to gastroesophageal reflux, cholelithiasis, abdominal panniculitis, back and musculoskeletal pain, and mental health disorders. In a German registry, female patients are younger and present with lower BMI than men (63). Males also showed higher prevalence of comorbidities, such as hypertension, T2DM, with and without insulin therapy, and sleep apnea, as well as complication rates (63). A meta-analysis demonstrated that mortality within 1 month after surgery was $0.1 \%$ in females but $4.7 \%$ in males (61).

Comparing patients selected for sleeve gastrectomy with laparoscopic Roux-en-Y gastric bypass (RYGB) revealed that female sex, gastroesophageal reflux disease, and an age of the surgeon above 40 years, were associated with greater probability of undergoing RYGB procedure (64). Higher BMI, presence of T2DM, as well as undergoing sleeve gastrectomy were associated with less weight loss. In general, complications include higher leakage and sepsis rates following RYGB or sleeve gastrectomy in males than females, but post-operative complications depend on age and BMI. Interestingly, a recent Australian study found that $27 \%$ of all bariatric procedures are revisions causing a huge socioeconomic burden. More than $80 \%$ of these revisions were 
performed in females (65). A prediction tool for postoperative complications after bariatric surgery includes six parameters of which gender (Odds ratio 1.4) is one of them, to identify low to high risk patients (66). The authors found in their multivariable analysis that next to male sex, the use of anticoagulants (OR 1.5), COPD (OR 2.3), dyslipidemia (OR 1.4), history of psychiatric disease (OR 1.3), and revision procedures (OR 1.5) are the other relevant predictors.

Severe obesity is often associated with hormonal imbalance. In a systematic review, gonadal dysfunction was observed in $36 \%$ of women featuring PCOS and $64 \%$ of men featuring male obesity-associated secondary hypogonadism (MOSH) (67). After bariatric surgery, this resolved in $96 \%$ of women and $87 \%$ of men, respectively, accompanied by increases of SHBG in both sexes and testosterone in men and decreases of estradiol in both sexes and testosterone in women, respectively. Furthermore, women showed an amelioration of menstrual dysfunction and typical signs of androgen excess as hirsutism. In a longitudinal study of obese patients with obstructive sleep apnea undergoing RYGB procedures, improvement of sleep parameters, obesity indices and metabolic outcomes were of similar magnitude in both sexes, except for triglycerides, which improved more in men than women (68). In another study, using gastric banding procedures $65 \%$ of the female compared to only $54 \%$ of the male diabetics had complete diabetes remission within 5 years after surgery and women also showed higher remission for hypertension and sleep apnea (69). Gastric banding may be less efficient in males than females, compared with other bariatric procedures, but at present there are no gender-tailored bariatric strategies.

Follow-up visits after bariatric surgery are essential to identify and prevent malnutrition and complications. A recent French retrospective study, including 16,620 patients who underwent bariatric surgery since 2009, found in a multivariable analysis that male sex, young age, no diagnosis of T2DM and poor 1 year follow-up was a predictor of poor 5-year follow-up (70). In studies with follow-up until 10 years after bariatric surgery, male sex was associated with an unfavorable energy and macronutrient intake and higher alcohol intake, which was also shown for younger age and sedentary behavior before surgery (71). Furthermore, male sex was associated with higher weight regain after RYGB procedure, next to other factors as white ethnicity and higher socioeconomic status (72). These studies demonstrate that men are at an increased risk for unhealthy behavior after a bariatric procedure, but also have higher mortality and complication rates, which is probably related to higher age, BMI, and an unhealthier condition already before surgery. Nevertheless, women have higher rates of revision procedures. Higher awareness of greater risk of the male population after bariatric surgery is needed to improve health outcome and probably more guidance is needed after bariatric surgery for male and female subjects at high risk for complications. More studies will help to further understand sex and gender differences after bariatric procedures.

Ethnical differences were observed in weight loss after bariatric surgery with African Americans losing less weight after RYGB and gastric banding than Caucasian patients (73). However, these differences were not explained by demographic, clinical, or behavioral characteristics. Further studies corroborated these findings and found lower weight loss after RYGB, sleeve gastrectomy, and gastric banding in African American compared with Hispanic and non-Hispanic white patients $(74,75)$. However, these differences did not influence the remission of co-morbidities (76).

In a study investigating race and gender effects bariatric surgery, significant higher weight loss after RYGB in non-Hispanic black man compared with non-Hispanic white men was found, whereas in women no such differences were reported. Ethnicity and sex were among the strongest predictors for weight loss next to age, weight at time of surgery, diet soda, and water intake (77).

Key points: bariatric surgery is very effective in weight reduction and thus prevention of T2DM. Women undergo bariatric surgery more often and show higher willingness to perform bariatric surgery. Male patients suffer more comorbidities before a surgical intervention and have higher complications and mortality rates after a surgery, women have higher revision rates. Men are at an increased risk for unhealthy behavior after a bariatric procedure. In African Americans, lower weight loss was observed (Table 1).

\section{REPRODUCTION/SEX HORMONES- RELATED HIGH-RISK GROUPS AND INTERVENTIONS}

Reproductive disturbances may help to identify subjects at risk in both sexes. Interestingly, a meta-analysis demonstrated the effects of sex hormones in men and women and revealed higher T2DM risk in subjects with sex hormone imbalance (78). Men with low testosterone levels had higher risk for T2DM, whereas in women associations between high testosterone levels and high diabetes risk were found. Among T2DM patients, men indicated a significantly higher sexual dissatisfaction compared to women and were in higher need for care in a Dutch study (79). ED was found in two-third of the men, whereas half of the women indicated low sexual desire and lubrication problems, respectively. In another study, a higher association of sexual dysfunction with depression was found in patients with T2DM in both sexes, particularly at higher age (80). A secondary analysis of the DPP found that reductions in visceral or subcutaneous adipose tissue were associated with significantly higher testosterone levels in men and SHBG levels in both sexes, which was independent of ethnicity (81).

\section{Men/Male-Specific Risk}

Low testosterone levels and/or ED may characterize malespecific high risk for T2DM, obesity, and the MEtSy $(6,82)$. In addition, poor glycemic control is associated with increasing risk for ED (83). A faster disease progression was reported in men with T2DM, with an ED diagnosis more than a decade earlier (84). Thus, ED may serve as an indicator for undetected impaired glucose tolerance. In patients with T2DM, systemic endothelial dysfunction and low-grade inflammation might be an underlying mechanism for ED and subsequent macrovascular complications $(83,85,86)$. In addition, hypogonadism is strongly associated with ED via direct and indirect metabolic 
effects and testosterone replacement might have positive effects on various regulators and mediators involved in erectile function $(86,87)$. A very recent systematic review investigating testosterone replacement therapy (TRT) in men suffering from hypogonadism found four trials which reported significantly better erectile function, sexual satisfaction, and higher sexual desire and libido, with no effects on mood or energy (88). A further review found improvements in components of the metabolic syndrome such as decreases in weight, BMI, waist circumference, glucose levels, HbA1c, cholesterol, and blood pressure in hypogonadal men receiving TRT, but also reporting conflicting literature (89). Thus, studies are needed to further evaluate the efficacy of TRT in hypogonadal men and in particular in the prevention of T2DM.

In general, lifestyle changes with improvement of healthy diet and physical activity, weight loss, the management of comorbidities, and good glycemic control are recommended for men with ED and T2DM (90). The positive effect of lifestyle intervention on erectile function, weight loss, and physical activity was shown in a post hoc analysis of middle-aged, overweight/obese men with T2DM in the LOOK AHEAD study (91). After 1 year in the intervention group, a significant improvement in erectile function, next to weight loss and increased physical activity, was found. A systematic review of 6 clinical trials, with 740 men with ED, reported an improvement of sexual function after at least 6 weeks of lifestyle or pharmacological intervention for cardiovascular risk factors (92). This was corroborated by a Japanese observational study, which found an inverse association of physical activity level with severity of ED in men with T2DM (93). Also, positive effects of lipid lowering compounds like statins were confirmed in men with ED (94), which is contrary to reports about subsequent ED as an adverse effect of statin therapy. A recent meta-analysis did not find any association between statin use and new onset ED (95). Several studies have shown that weight loss, increase of physical activity, smoking and alcohol cessation, as well as stress reduction, are important prevention strategies to tackle sexual dysfunction and other health implications (96). So far, few studies examined the effect of physical fitness in men with ED on health outcomes. In the DPP intensive lifestyle intervention was associated with increased testosterone levels, whereas these changes were not found with metformin or placebo. However, testosterone increases were not associated with significant changes in mood in the lifestyle intervention or placebo arms, but significantly improved depressive symptoms were found with increasing testosterone levels in the metformin arm (97).

In a study examining men with pharmacologically treated ED from the Henry Ford Exercise Testing (FIT) project, the associations of exercise capacity with cardiovascular and metabolic outcomes were investigated (98). A reduction of $16 \%$ in all-cause mortality with increasing fitness and non-significant reductions for major adverse cardiovascular events or incident diabetes were identified. A window of opportunity of up to 5 years was discussed from the onset of ED to a symptomatic cardiovascular event (99). Thus, early introduced preventive approaches seem to be important to improve ED and avoid cardiometabolic disease progression. However, limited evidence exits about lifestyle intervention in men with ED and subsequent disease progression, and thus, further studies are needed.

\section{Women/Female-Specific Risk}

In women, reproductive factors and reproductive history help to identify women at higher risk for T2DM. Early menarche, irregular cycles, higher androgen levels or PCOS, and most of all a history of gestational diabetes (GDM), affecting approximately $15 \%$ of pregnant women, are related to higher diabetes risk $(6,100)$. The EPIC-InterAct study reported an association of early menarche between 8 and 11 years of age with 70\% higher T2DM risk compared to menarche at 13 years of age (101). This was corroborated by a systematic review showing about $22 \%$ higher risk. A relation between higher prepubertal BMI and younger age of menarche onset is well-known; nonetheless in this study, an independent association between menarche and T2DM risk was shown (101). Older age at menarche did not decrease T2DM risk. Decreased insulin sensitivity and higher obesity risk in young female adults were also reported for early menarche, as well as higher risk for NAFLD (102-104), ectopic lipid accumulation, and GDM. Interestingly, application of metformin at age 8 years was able to delay menarche by more than 1 year and increased body height and reduced body weight, hepatic lipid accumulation and insulin, androgen and lipid levels in girls born with low body weight and precocious pubarche (105). Importantly, timing of metformin onset seems important; as in a further investigation, differences with higher prevalence of hirsutism, androgen excess, oligomenorrhea, and PCOS were found in those girls with later treatment start of metformin (106).

A higher susceptibility for metabolic disease and development of T2DM and GDM is well known in patients with PCOS with reported relative risks of about 2.0, and 3.9 with BMI above 30 for T2DM and 2.9 for GDM (107). Women with PCOS have higher prevalence of overweight/obesity including central obesity and BMI and show higher associations with increased insulin resistance and hyperinsulinism (108) compared with women without PCOS. Moreover, a genetic predisposition is widely discussed, which leads to polycystic ovary formation and finally to excess androgen production, $\mathrm{LH}$ production, and insulin resistance with hyperinsulinemia aggravated by excess weight and further stimulation of the ovarial theka cells to produce testosterone, which causes a plethora of variations in symptoms. Lifestyle intervention and change are very important in the prevention of T2DM for subjects at high risk as shown in several diabetes prevention trials (5). Large lifestyle intervention studies including PCOS women and testing diabetes prevention strategies are scarce. So far, lifestyle changes are reported to be beneficial and ameliorate fasting glucose (107). A meta-analysis provides evidence that in women with PCOS, a combination of lifestyle intervention and metformin is more effective in weight reduction and reduction of subcutaneous fat after 6 months of combined treatment compared to metformin alone or lifestyle and placebo groups, although no effects were documented on other metabolic parameters as insulin resistance, glucose, or lipid levels (109). Furthermore, higher probability of menstruation was reported in the lifestyle and metformin group. Another meta-analysis investigating the metabolic effects of myoinositol supplementation compared to control found beneficial effects of myoinositol with lower insulin resistance and insulin levels, as well as higher SHBG levels and a trend for reductions of androgens (110). However, the authors 
report huge heterogeneity of all included studies, which allows limited generalization, but plenty of space for new interesting research questions. Other promising new approaches including DPP4 inhibitors were tested over a 12 -week period and have proven improvements in beta cell function and insulin resistance with lower conversion rates to T2DM (111) in the combined DPP4 inhibitor and lifestyle intervention group compared with lifestyle intervention alone. Nonetheless, this small pilot study included only 30 obese, metformin intolerant patients and thus these beneficial observations should not be over-interpreted as long as no further confirmatory studies and support these findings. Furthermore, GLP1 receptor agonists in obese PCOS women were successful in reducing weight and androgen levels but did not improve insulin sensitivity or menstrual irregularities (112).

Prevalence rates of obesity are increasing, which also affects women in childbearing age and represents a prominent risk factor of GDM (113). A cumulated GDM prevalence of 39\% across the whole pregnancy was observed in obese pregnant women across Europe using IADPSG/WHO 2013 criteria (114). These women presented with a GDM prevalence of nearly $24 \%$ already before 20 weeks of gestation and a clustering of many factors of the MetSy (115).

Thus, evidence based prevention approaches in pregnancy to avoid GDM development (Table 2) and subsequent complications have to be found as women with a history of GDM have a 7.5-fold higher risk of T2DM development and bear a higher risk of consecutive cardiovascular disease $(116,117)$.

A subgroup analysis of women with prediabetes at baseline included in the DPP and followed over 10 years demonstrated that women with a history of GDM have a $48 \%$ higher diabetes progression risk than women with normal glucose tolerance during pregnancy (129). In addition, intensive lifestyle changes reduced diabetes risk by $35 \%$ and metformin therapy by $40 \%$ in women with prior GDM, while in the comparison group only lifestyle intervention resulted in a risk reduction of 30\% (129). This clearly shows the effectiveness of lifestyle intervention to prevent T2DM progression in female high-risk collectives, such as women with GDM. Accordingly, lifestyle modification might be a potential approach to prevent GDM progression already in pregnancy.

However, evidence of successful lifestyle intervention in pregnancy is conflicting. RCTs investigating the effects of lifestyle interventions on GDM prevention in high risk overweight/ obese pregnant women yield controversial results (Table 2). Recent large scale RCTs were not able to show any significant reductions of GDM prevalence or macrosomia in offspring in the intervention groups. These studies included predominately obese pregnant women. Difficulties in motivation to participate in these studies were reported with inclusion rates of $20 \%$ of the invited women (123). Furthermore, adherence to maintain lifestyle changes throughout pregnancy was difficult. The small differences observed in weight gain in pregnancy between intervention and control groups may explain the lack of success in reduction of GDM or LGA risk (130).

Although the recently published DALI lifestyle study, investigating the effectiveness of physical activity and/or dietary intervention in decreasing GDM risk, was able to show significantly lower weight gain in the combined healthy eating and physical activity intervention group compared to usual care, there was no difference between intervention and usual care groups in glucose or insulin parameters, insulin resistance or birthweight (126).

The authors of a recent review, evaluating lifestyle intervention, dietary supplementation or pharmacological therapy for GDM prevention in women with and without risk factors for GDM, reported difficulties to give recommendations due to the complexity and heterogeneity of these trials (131). Neither combined (diet and exercise) lifestyle nor dietary interventions were able to reduce GDM progression in women without risk factors and an unclear evidence was described for physical activity. However, in obese women, dietary measures reduced GDM risk and macrosomia, but physical activity was not effective. Interestingly, supplementation with probiotics or myoinositol reduced GDM risk. Of note, pharmacological approaches, as shown for metformin, were not able to reduce GDM incidence in obese women or women with PCOS (131).

Therefore, initiation of lifestyle modification in early pregnancy might be too late. This is supported by a meta-analysis targeting increased physical activity before and during pregnancy (132). Much greater benefit was shown in studies starting intervention before pregnancy than in early pregnancy.

A recently presented large retrospective study at the American Society for Reproductive Medicine Scientific Congress including more than 78,000 women demonstrated that women with infertility have higher all-cause mortality compared to fertile women (133). Interestingly, diabetes was identified as a main primary cause of mortality, although similar diabetes prevalence in both groups was found.

A prospective cohort analysis of postmenopausal women between 50 and 79 years of age of the Women's Health initiative revealed an association between the development of T2DM and short (less than 30 years) and long (more than 45 years) reproductive periods determined as duration from menarche to last menstrual period (134). Interestingly, HRT after menopause reduces the risk of development of T2DM and improves glycemic control in women with T2DM (118). Improvements in insulin secretion and sensitivity as well as beta cell function were reported. However, the physiological mechanisms remain elusive. Taking the existing evidence into account, the authors conclude that hormone replacement therapy within 10 years after menopause and below 60 years of age is effective in preventing development of T2DM and cardiovascular disease. Nonetheless, adverse effects of estrogen therapy need to be considered carefully before initiation.

Key points: hormonal imbalance of sex hormones and reproductive disorders, such as PCOS in women or ED in men, are associated with higher T2DM risk. Lifestyle interventions may improve hormonal imbalance and are also associated with improved cardiometabolic parameters in ED, hypogonadism and PCOS, whereas lifestyle interventions starting in early pregnancy did not affect GDM risk or pregnancy outcomes in most studies. Improvements in components of the metabolic syndrome and glycemic control were found after TRT and HRT. Myoinositol supplementation was associated with lower GDM risk and better glycemic control in women with PCOS, whereas metformin did not improve metabolic parameters in obese women with GDM or women with PCOS (Table 1). 
TABLE 2 | Representation of GDM prevention trials (RCTs or meta-analysis of RCTs).

\begin{tabular}{|c|c|c|c|c|}
\hline Population & Interventions & Results & Additional information & Reference \\
\hline $\begin{array}{l}2,873 \text { healthy pregnant } \\
\text { women, low level } \\
\text { of physical activity } \\
\text { (exercising }<20 \text { min } \\
\text { on }<3 \text { days per week), } \\
1,434 \text { intervention and } \\
1,439 \text { control group }\end{array}$ & $\begin{array}{l}\text { Physical exercise programs that included } \\
\text { low to moderate intensity exercises. No } \\
\text { restrictions on frequency, duration, or type } \\
\text { of training }\end{array}$ & $\begin{array}{l}\text { Lower GDM risk ( } 30 \% \\
\text { risk reduction) } \\
\text { Lower maternal weight } \\
\text { gain }\end{array}$ & $\begin{array}{l}\text { GDM risk reduction and lower weight gain especially } \\
\text { with physical activity program performed throughout } \\
\text { pregnancy. } \\
\text { No serious adverse effects }\end{array}$ & (119) \\
\hline $\begin{array}{l}4,983 \text { women and their } \\
\text { babies }\end{array}$ & $\begin{array}{l}\text { Combined diet and exercise interventions } \\
\text { compared with standard care }\end{array}$ & $\begin{array}{l}\text { No GDM risk reduction. } \\
\text { No difference in maternal } \\
\text { weight gain }\end{array}$ & $\begin{array}{l}\text { Less preterm delivery; } \\
\text { Comparable rates of cesarean section, LGA, stillbirth } \\
\text { and neonatal death, shorter duration of hospital stay }\end{array}$ & (120) \\
\hline $\begin{array}{l}132 \text { women with BMl } \\
>25 \mathrm{~kg} / \mathrm{m}^{2}\end{array}$ & $\begin{array}{l}\text { Four-step multidisciplinary antenatal care } \\
\text { (continuity of obstetric provider, regular } \\
\text { weighing, nutritional and psychological } \\
\text { advice) vs standard obstetric antenatal care }\end{array}$ & $\begin{array}{l}\text { Lower incidence of GDM } \\
\text { (83\% less). } \\
\text { Lower maternal weight } \\
\text { gain }\end{array}$ & Comparable birth weight of newborns & $(121)$ \\
\hline $\begin{array}{l}2,152 \text { pregnant } \\
\text { women, } \mathrm{BMl} \geq 25 \\
\mathrm{~kg} / \mathrm{m}^{2}, 10-20 \text { weeks } \\
\text { of pregnancy }\end{array}$ & $\begin{array}{l}\text { Early lifestyle intervention consisting of } \\
\text { healthy eating advice and increasing physical } \\
\text { activity compared to routine measures }\end{array}$ & $\begin{array}{l}\text { No GDM risk reduction. }{ }^{a} \\
\text { No difference in maternal } \\
\text { weight gain }^{\mathrm{a}}\end{array}$ & $\begin{array}{l}\text { LGA not significantly different, less infants in } \\
\text { intervention group with weight }>4 \mathrm{~kg} \text {, no differences } \\
\text { in hypertension, pre-eclampsia, cesarean section, } \\
\text { NICU admission, and hypoglycemia }\end{array}$ & (122) \\
\hline $\begin{array}{l}1,555 \text { pregnant } \\
\text { women, } \mathrm{BMI} \geq 30 \\
\mathrm{~kg} / \mathrm{m}^{2}, 15-19 \text { weeks } \\
\text { of pregnancy }\end{array}$ & $\begin{array}{l}\text { Behavioral intervention or standard antenatal } \\
\text { care, once a week through eight health } \\
\text { trainer-led sessions to endorse healthy eating }\end{array}$ & $\begin{array}{l}\text { No GDM risk reduction. }{ }^{\text {a }} \\
\text { Lower maternal weight }^{\text {gain. }}{ }^{a}\end{array}$ & $\begin{array}{l}\text { LGA not significantly different, no significant } \\
\text { differences in adverse birth outcomes. Increase in } \\
\text { physical activity, reduction in dietary glycemic load, } \\
\text { and maternal sum of skinfold thickness }\end{array}$ & (123) \\
\hline $\begin{array}{l}269 \text { pregnant women, } \\
\text { history of GDM or } \\
\text { BMI } \geq 30 \mathrm{~kg} / \mathrm{m}^{2} \text {, before } \\
20 \text { weeks gestation }\end{array}$ & $\begin{array}{l}\text { Individualized combined lifestyle intervention, } \\
\text { focus on diet, physical activity, and weight } \\
\text { control }\end{array}$ & $\begin{array}{l}\text { Lower GDM risk ( } 39 \% \\
\text { risk reduction). } \\
\text { Lower maternal weight } \\
\text { gain }\end{array}$ & $\begin{array}{l}\text { Increase in physical activity and improvement of } \\
\text { dietary quality }\end{array}$ & (124) \\
\hline $\begin{array}{l}150 \text { pregnant women, } \\
\mathrm{BMl} \leq 29 \mathrm{~kg} / \mathrm{m}^{2} \text {, before } \\
20 \text { weeks gestation }\end{array}$ & $\begin{array}{l}\text { Randomization to three intervention groups: } \\
\text { healthy eating }(\mathrm{HE}) \text {, physical activity }(\mathrm{PA}) \text {, } \\
\text { and combined healthy eating and physical } \\
\text { activity, following principles of motivational } \\
\text { interviewing }\end{array}$ & $\begin{array}{l}\text { No significant differences } \\
\text { in GDM risk. } \\
\text { Lower gestational weight } \\
\text { gain in HE compared } \\
\text { to PA }\end{array}$ & $\begin{array}{l}\text { Comparable HOMA indices in all three intervention } \\
\text { groups. Fasting glucose lower in HE at 35-37 weeks } \\
\text { compared to PA. } \\
20 \% \text { of all women under the weight gain target of } \\
<5 \mathrm{~kg} \text {, in total after } 37 \text { weeks } 32 \% \text { GDM in obese } \\
\text { pregnant women }\end{array}$ & (125) \\
\hline $\begin{array}{l}436 \text { pregnant women, } \\
\mathrm{BMI} \leq 29 \mathrm{~kg} / \mathrm{m}^{2} \text {, before } \\
20 \text { weeks gestation }\end{array}$ & $\begin{array}{l}\text { Four groups, healthy eating (HE), physical } \\
\text { activity (PA), combined healthy eating and } \\
\text { physical activity (HE + PA), usual care } \\
\text { (UC), following principles of motivational } \\
\text { interviewing }\end{array}$ & $\begin{array}{l}\text { No significant differences } \\
\text { in GDM risk. } \\
\text { Lower gestational } \\
\text { weight gain in HE + PA } \\
\text { compared to UC }\end{array}$ & $\begin{array}{l}\text { No Improvements in glucose or insulin parameters } \\
\text { or HOMA IR. } \\
\text { Similar birth weight, LGA, or SGA rates }\end{array}$ & (126) \\
\hline $\begin{array}{l}450 \text { pregnant women, } \\
\mathrm{BMI} \geq 35 \mathrm{~kg} / \mathrm{m}^{2} \\
12-18 \text { weeks gestation }\end{array}$ & $\begin{array}{l}\text { Metformin, at a dose of } 3.0 \mathrm{~g} \text { per day, or } \\
\text { placebo }\end{array}$ & $\begin{array}{l}\text { No significant differences } \\
\text { in GDM risk. } .^{\text {a }} \\
\text { Lower maternal weight } \\
\text { gain }^{a}\end{array}$ & $\begin{array}{l}\text { No significant difference in birth weight. } \\
\text { Lower incidence of preeclampsia. } \\
\text { Higher incidence of side effects in Metformin group }\end{array}$ & (127) \\
\hline $\begin{array}{l}449 \text { pregnant women, } \\
\mathrm{BMI} \geq 30 \mathrm{~kg} / \mathrm{m}^{2} \\
12-16 \text { weeks gestation }\end{array}$ & $\begin{array}{l}\text { Metformin, at a dose of } 2.5 \mathrm{~g} \text { per day } \\
\text { (maximum dose), or placebo }\end{array}$ & $\begin{array}{l}\text { No significant differences } \\
\text { in GDM risk. }{ }^{a} \\
\text { No significant difference } \\
\text { in maternal weight gain }{ }^{a}\end{array}$ & $\begin{array}{l}\text { No significant difference in birth weight. } \\
\text { No significant differences in HOMA IR or other } \\
\text { metabolic parameters. }^{\text {a }} \\
\text { No significant differences in combined adverse outcomes. } \\
\text { Higher incidence of side effects in Metformin group }\end{array}$ & (128) \\
\hline
\end{tabular}

aSecondary outcomes.

$R C T$, randomized controlled trial; BMI, body mass index; GDM, gestational diabetes mellitus; HE, healthy eating; PA, physical activity; IR, insulin resistance; RR, relative risk; CI, confidence interval; NICU, neonatal intensive care unit; LGA, large for gestational age; SGA, small for gestational age.

\section{RECOMMENDATIONS FOR CLINICAL PRACTICE AND FUTURE RESEARCH}

In men and women, obesity and sedentary lifestyle are major risk factors for T2DM and weight reduction, maintenance of normal weight and physical fitness can effectively reduce the risk of diabetes. This needs to start early in life. However, many patients at risk have problems to participate in and adhere to lifestyle intervention. Same-sex-group-based exercise programs based on a social identity approach may be more successful, probably due to better motivation, adherence behavior and social congruence, but implementations and success need to be further investigated. This also applies for culturally tailored approaches. Sex-specific and culturally tailored initiatives may be very promising in tackling 
obesity. They could reach a great number and specific subgroups of males and females who are currently underrepresented in common gender-integrated weight loss programs. A group of special interest are Asian and Asian Americans, who should be screened for T2DM at BMI $23 \mathrm{~kg} / \mathrm{m}^{2}$, which is lower than for other ethnical groups (8).

Results of several projects targeting obese and overweight male sports fans are very promising, and further examples are expected in the next few years. Indeed, there is also a need for such programs for women and the ideal setting to meet these women and engage them into a lifestyle and weight reduction program need to be identified. Although in Scandinavian countries, "Football Fitness" was able to reach a large number of women at risk, even on a population scale with the high potential to improve health outcome, this approach might not be feasible in other regions and cultures across the world. As several other aspects-such as parenting-are relevant in women's lives potential programs also need to address these demands. Nonetheless, most programs so far were not directly addressed to investigate T2DM prevention, and therefore, studies aiming to investigate prevention of T2DM in men and women with different sociocultural and ethnical background are urgently needed.

In both sexes, reproductive factors and reproductive history may help to identify better those subjects at higher risk, such as women with early menarche, irregular cycles, PCOS, or women with a history of GDM. In males, ED can help to characterize a group at high risk. In the ADA guidelines, the importance of sex-specific aspects in diabetes development was addressed, and sex-specific differences were included in the "Diabetes Risk Test" (8). Male sex in general and women with a history of GDM are associated with higher diabetes risk. Except for GDM, information about the effectiveness of lifestyle intervention or pharmaceutical approaches in the prevention of T2DM in women with PCOS or men with ED is limited and further studies are needed.

Currently, mostly women are willing to perform bariatric surgery to reduce weight and significantly higher revision surgeries are reported to be performed in women. Data point to a higher mortality risk in men, which urgently needs closer investigation, but probably a higher age, BMI at surgery or comorbidities are potential risk factors. Sex differences are reported in complication following bariatric procedures. RYGB was associated with a good outcome regarding weight loss and several other parameters in both sexes, whereas gastric banding seems to be less efficient in men. Furthermore, male sex is often mentioned in literature to be associated with higher complication rate and worse follow-up outcome after bariatric surgery. Lower weight loss after RYGB, sleeve

\section{REFERENCES}

1. International Diabetes Federation. Diabetes: Facts and Figures. (2017). Available from: http://www.idf.org/about-diabetes/facts-figures (Accessed: January 9, 2018).

2. Tuomilehto J, Schwarz P, Lindstrom J. Long-term benefits from lifestyle interventions for type 2 diabetes prevention: time to expand the efforts. Diabetes Care (2011) 34(Suppl 2):S210-4. doi:10.2337/dc11-s222

3. Boyle JP, Thompson TJ, Gregg EW, Barker LE, Williamson DF. Projection of the year 2050 burden of diabetes in the US adult population: dynamic modeling of incidence, mortality, and prediabetes prevalence. Popul Health Metr (2010) 8:29. doi:10.1186/1478-7954-8-29 gastrectomy, and gastric banding was reported in African American compared with Hispanic and non-Hispanic white patients.

Although trials investigating lifestyle or pharmacological intervention in males and females at risk were promising so far, there is need of more research on biological and psychosocial differences and of evidence-based sex-sensitive and culturally tailored concepts of prevention. However, so far most published study results are derived from secondary post hoc analysis and thus are mostly insufficiently powered. Thus, further prevention trials are necessary to investigate sex, gender, and ethnical differences in effectiveness of prevention strategies and short- and long-term health outcomes, such as cardiovascular endpoints. Moreover, adverse events and potential sex-specific differences need to be reported in prevention trials using glucose lowering compounds. They are widely not documented and thus essential information is still missing.

In summary, future studies, should consider and investigate sex and gender as well as ethnical differences in diabetes and cardiovascular prevention trials to a much higher extent than so far performed. The consideration and implementation of sex/gender differences in clinical practice and in diagnostic and therapeutic concepts-if necessary-will improve quality of care and reduce the burden of growing diabetes numbers. This considerably will lower health care costs worldwide. Sex-sensitive and culturally tailored prevention programs and sex-specific education, lifestyle programs, and drug therapy will potentially contribute to better care of patients with T2DM in the future.

\section{AUTHOR CONTRIBUTIONS}

$\mathrm{JH}$ and $\mathrm{AK}-\mathrm{W}$ contributed to conception or design, acquisition, analysis, or interpretation of the manuscript. JH and AK-W drafted and critically revised the manuscript. JH and AK-W gave final approval and agreed to be accountable for all aspects of work ensuring integrity and accuracy.

\section{ACKNOWLEDGMENTS}

We thank Anita Thomas for her assistance in preparation of the manuscript and Katharina Maruszczak for providing support as a language editor.

\section{FUNDING}

This study was funded by a WWTF grant to AKW: project number MA16-045.

4. Backholer K, Peeters A, Herman WH, Shaw JE, Liew D, Ademi Z, et al. Diabetes prevention and treatment strategies: are we doing enough? Diabetes Care (2013) 36(9):2714-9. doi:10.2337/DC12-2501

5. Glechner A, Harreiter J, Gartlehner G, Rohleder S, Kautzky A, Tuomilehto J, et al. Sex-specific differences in diabetes prevention: a systematic review and meta-analysis. Diabetologia (2015) 58(2):242-54. doi:10.1007/s00125-014-3439-x

6. Kautzky-Willer A, Harreiter J, Pacini G. Sex and gender differences in risk, pathophysiology and complications of type 2 diabetes mellitus. Endocr Rev (2016) 37(3):278-316. doi:10.1210/er.2015-1137

7. Kautzky-Willer A, Harreiter J. Sex and gender differences in therapy of type 2 diabetes. Diabetes Res Clin Pract (2017) 131:230-41. doi:10.1016/j. diabres.2017.07.012 
8. American Diabetes Association. 2. Classification and diagnosis of diabetes. Diabetes Care (2018) 41(Suppl 1):S13-27. doi:10.2337/dc18-S002

9. Centers for Disease Control and Prevention. National Diabetes Statistics Report, 2017. Atlanta, GA: Centers for Disease Control and Prevention, U.S. Dept of Health and Human Services (2017).

10. Araneta MR, Kanaya AM, Hsu WC, Chang HK, Grandinetti A, Boyko EJ, et al. Optimum BMI cut points to screen Asian Americans for type 2 diabetes. Diabetes Care (2015) 38(5):814-20. doi:10.2337/dc14-2071

11. Wardle J, Haase AM, Steptoe A, Nillapun M, Jonwutiwes K, Bellisle F. Gender differences in food choice: the contribution of health beliefs and dieting. Ann Behav Med (2004) 27(2):107-16. doi:10.1207/s15324796abm2702_5

12. Kanter R, Caballero B. Global gender disparities in obesity: a review. $A d v$ Nutr (2012) 3(4):491-8. doi:10.3945/an.112.002063

13. Merlotti C, Morabito A, Pontiroli AE. Prevention of type 2 diabetes; a systematic review and meta-analysis of different intervention strategies. Diabetes Obes Metab (2014) 16(8):719-27. doi:10.1111/dom.12270

14. Funk LM, Jolles S, Fischer LE, Voils CI. Patient and referring practitioner characteristics associated with the likelihood of undergoing bariatric surgery: a systematic review. JAMA Surg (2015) 150(10):999-1005. doi:10.1001/ jamasurg.2015.1250

15. Lovejoy JC, Sainsbury A; Stock Conference 2008 Working Group. Sex differences in obesity and the regulation of energy homeostasis. Obes Rev (2009) 10(2):154-67. doi:10.1111/j.1467-789X.2008.00529.x

16. Bays HE, Bazata DD, Fox KM, Grandy S, Gavin JR III; SHIELD Study Group. Perceived body image in men and women with type 2 diabetes mellitus: correlation of body mass index with the figure rating scale. Nutr J (2009) 8:57. doi:10.1186/1475-2891-8-57

17. Kautzky-Willer A, Handisurya A. Metabolic diseases and associated complications: sex and gender matter! Eur J Clin Invest (2009) 39(8):631-48. doi:10.1111/j.1365-2362.2009.02161.x

18. Gerovasili V, Agaku IT, Vardavas CI, Filippidis FT. Levels of physical activity among adults 18-64 years old in 28 European countries. Prev Med (2015) 81:87-91. doi:10.1016/j.ypmed.2015.08.005

19. Weber MB, Ranjani H, Staimez LR, Anjana RM, Ali MK, Narayan KM, et al. The stepwise approach to diabetes prevention: results from the D-CLIP randomized controlled trial. Diabetes Care (2016) 39(10):1760-7. doi:10.2337/ dc16-1241

20. Ranjani H, Weber MB, Anjana RM, Lakshmi N, Narayan KM, Mohan V. Recruitment challenges in a diabetes prevention trial in a low- and middleincome setting. Diabetes Res Clin Pract (2015) 110(1):51-9. doi:10.1016/j. diabres.2015.07.013

21. Perreault L, Ma Y, Dagogo-Jack S, Horton E, Marrero D, Crandall J, et al. Sex differences in diabetes risk and the effect of intensive lifestyle modification in the Diabetes Prevention Program. Diabetes Care (2008) 31(7):1416-21. doi: $10.2337 / \mathrm{dc} 07-2390$

22. Rockette-Wagner B, Storti KL, Dabelea D, Edelstein S, Florez H, Franks PW, et al. Activity and sedentary time 10 years after a successful lifestyle intervention: the Diabetes Prevention Program. Am J Prev Med (2016) 52(3):292-9. doi:10.1016/j.amepre.2016.10.007

23. Kohl HW III, Craig CL, Lambert EV, Inoue S, Alkandari JR, Leetongin G, et al. The pandemic of physical inactivity: global action for public health. Lancet (2012) 380(9838):294-305. doi:10.1016/S0140-6736(12)60898-8

24. Sallis JF, Bull F, Guthold R, Heath GW, Inoue S, Kelly P, et al. Progress in physical activity over the Olympic quadrennium. Lancet (2016) 388(10051):1325-36. doi:10.1016/S0140-6736(16)30581-5

25. Li G, Zhang P, Wang J, An Y, Gong Q, Gregg EW, et al. Cardiovascular mortality, all-cause mortality, and diabetes incidence after lifestyle intervention for people with impaired glucose tolerance in the Da Qing Diabetes Prevention Study: a 23-year follow-up study. Lancet Diabetes Endocrinol (2014) 2(6):474-80. doi:10.1016/S2213-8587(14)70057-9

26. West DS, Elaine Prewitt T, Bursac Z, Felix HC. Weight loss of black, white, and Hispanic men and women in the Diabetes Prevention Program. Obesity (Silver Spring) (2008) 16(6):1413-20. doi:10.1038/oby.2008.224

27. Ritchie ND, Christoe-Frazier L, McFann KK, Havranek EP, Pereira RI. Effect of the National Diabetes Prevention Program on weight loss for Englishand Spanish-speaking Latinos. Am J Health Promot (2018) 32(3):812-5. doi:10.1177/0890117117698623

28. Cezard G, Douglas A, Gill JM, McKnight J, Sheikh A, Wallia S, et al. Did the weight loss in the Prevention of Diabetes and Obesity in South Asians
(PODOSA) trial differ by sex? An exploratory analysis. Public Health (2017) 145:67-9. doi:10.1016/j.puhe.2016.12.004

29. Rush EC, Chandu V, Plank LD. Reduction of abdominal fat and chronic disease factors by lifestyle change in migrant Asian Indians older than 50 years. Asia Pac J Clin Nutr (2007) 16(4):671-6.

30. Patel RM, Misra R, Raj S, Balasubramanyam A. Effectiveness of a GroupBased Culturally Tailored Lifestyle Intervention Program on changes in risk factors for type 2 diabetes among Asian Indians in the United States. J Diabetes Res (2017) 2017:2751980. doi:10.1155/2017/2751980

31. Lagisetty PA, Priyadarshini S, Terrell S, Hamati M, Landgraf J, Chopra V, et al. Culturally targeted strategies for diabetes prevention in minority population. Diabetes Educ (2017) 43(1):54-77. doi:10.1177/0145721716683811

32. Gumber A, Gumber L. Improving prevention, monitoring and management of diabetes among ethnic minorities: contextualizing the six G's approach. BMC Res Notes (2017) 10(1):774. doi:10.1186/s13104-017-3104-9

33. Neumann A, Lindholm L, Norberg M, Schoffer O, Klug SJ, Norstrom F. The cost-effectiveness of interventions targeting lifestyle change for the prevention of diabetes in a Swedish primary care and community based prevention program. Eur J Health Econ (2016) 18(7):905-19. doi:10.1007/ s10198-016-0851-9

34. Robertson C, Avenell A, Boachie C, Stewart F, Archibald D, Douglas F, et al. Should weight loss and maintenance programmes be designed differently for men? A systematic review of long-term randomised controlled trials presenting data for men and women: the ROMEO project. Obes Res Clin Pract (2016) 10(1):70-84. doi:10.1016/j.orcp.2015.04.005

35. Blackman Carr LT, Samuel-Hodge C, Ward DS, Evenson KR, Bangdiwala SI, Tate DF. Racial differences in weight loss mediated by engagement and behavior change. Ethn Dis (2018) 28(1):43-8. doi:10.18865/ed.28.1.43

36. Gower BA, Alvarez JA, Bush NC, Hunter GR. Insulin sensitivity affects propensity to obesity in an ethnic-specific manner: results from two controlled weight loss intervention studies. Nutr Metab (Lond) (2013) 10(1):3. doi:10.1186/1743-7075-10-3

37. Svetkey LP, Ard JD, Stevens VJ, Loria CM, Young DY, Hollis JF, et al. Predictors of long-term weight loss in adults with modest initial weight loss, by sex and race. Obesity (Silver Spring) (2012) 20(9):1820-8. doi:10.1038/oby.2011.88

38. Keith NR, Hemmerlein KA, Clark DO. Weight loss attitudes and social forces in urban poor Black and White women. Am J Health Behav (2015) 39(1):34-42. doi:10.5993/AJHB.39.1.4

39. Carson TL, Eddings KE, Krukowski RA, Love SJ, Harvey-Berino JR, West DS. Examining social influence on participation and outcomes among a network of behavioral weight-loss intervention enrollees. J Obes (2013) 2013:480630. doi:10.1155/2013/480630

40. Rosas LG, Thiyagarajan S, Goldstein BA, Drieling RL, Romero PP, Ma J, et al. The effectiveness of two community-based weight loss strategies among obese, low-income US Latinos. J Acad Nutr Diet (2015) 115(4):537-50.e2. doi:10.1016/j.jand.2014.10.020

41. Juraschek SP, Blaha MJ, Blumenthal RS, Brawner C, Qureshi W, Keteyian SJ, et al. Cardiorespiratory fitness and incident diabetes: the FIT (Henry Ford ExercIse Testing) project. Diabetes Care (2015) 38(6):1075-81. doi:10.2337/ dc14-2714

42. Dunlop WL, Beauchamp MR. En-gendering choice: preferences for exercising in gender-segregated and gender-integrated groups and consideration of overweight status. Int J Behav Med (2011) 18(3):216-20. doi:10.1007/ s12529-010-9125-6

43. Burton NW, Khan A, Brown WJ. How, where and with whom? Physical activity context preferences of three adult groups at risk of inactivity. Br J Sports Med (2012) 46(16):1125-31. doi:10.1136/bjsports-2011-090554

44. Beauchamp MR, Harden SM, Wolf SA, Rhodes RE, Liu Y, Dunlop WL, et al. Group based physical activity for older adults (GOAL) randomized controlled trial: study protocol. BMC Public Health (2015) 15:592. doi:10.1186/ s12889-015-1909-9

45. Stevens M, Rees T, Coffee P, Steffens NK, Haslam SA, Polman R. A social identity approach to understanding and promoting physical activity. Sports Med (2017) 47(10):1911-8. doi:10.1007/s40279-017-0720-4

46. Dunlop WL, Beauchamp MR. Does similarity make a difference? Predicting cohesion and attendance behaviors within exercise group settings. Group Dyn Theory Res Pract (2011) 15(3):258-66. doi:10.1037/a0023642

47. Hunt K, Wyke S, Gray CM, Anderson AS, Brady A, Bunn C, et al. A gendersensitised weight loss and healthy living programme for overweight and 
obese men delivered by Scottish Premier League football clubs (FFIT): a pragmatic randomised controlled trial. Lancet (2014) 383(9924):1211-21. doi:10.1016/S0140-6736(13)62420-4

48. van Nassau F, van der Ploeg HP, Abrahamsen F, Andersen E, Anderson AS, Bosmans JE, et al. Study protocol of European Fans in Training (EuroFIT): a four-country randomised controlled trial of a lifestyle program for men delivered in elite football clubs. BMC Public Health (2016) 16:598. doi:10.1186/s12889-016-3255-y

49. Gill DP, Blunt W, De Cruz A, Riggin B, Hunt K, Zou G, et al. Hockey Fans in Training (Hockey FIT) pilot study protocol: a gender-sensitized weight loss and healthy lifestyle program for overweight and obese male hockey fans. BMC Public Health (2016) 16(1):1096. doi:10.1186/s12889-0163730-5

50. Petrella RJ, Gill DP, Zou G, DE Cruz A, Riggin B, Bartol C, et al. Hockey fans in training: a pilot pragmatic randomized controlled trial. Med Sci Sports Exerc (2017) 49(12):2506-16. doi:10.1249/MSS.0000000000001380

51. Caperchione CM, Bottorff JL, Oliffe JL, Johnson ST, Hunt K, Sharp P, et al. The HAT TRICK programme for improving physical activity, healthy eating and connectedness among overweight, inactive men: study protocol of a pragmatic feasibility trial. BMJOpen (2017) 7(9):e016940. doi:10.1136/ bmjopen-2017-016940

52. Crump C, Sundquist J, Winkleby MA, Sieh W, Sundquist K. Physical fitness among Swedish Military Conscripts and long-term risk for type 2 diabetes mellitus: a cohort study. Ann Intern Med (2016) 164(9):577-84. doi:10.7326/ M15-2002

53. Twig G, Tirosh A, Leiba A, Levine H, Ben-Ami Shor D, Derazne E, et al. BMI at age 17 years and diabetes mortality in midlife: a nationwide cohort of 2.3 million adolescents. Diabetes Care (2016) 39(11):1996-2003. doi:10.2337/ dc16-1203

54. Krustrup P, Helge EW, Hansen PR, Aagaard P, Hagman M, Randers MB, et al. Effects of recreational football on women's fitness and health: adaptations and mechanisms. Eur JAppl Physiol (2018) 118(1):11-32. doi:10.1007/ s00421-017-3733-7

55. Krustrup P, Skoradal MB, Randers MB, Weihe P, Uth J, Mortensen J, et al. Broad-spectrum health improvements with one year of soccer training in inactive mildly hypertensive middle-aged women. Scand JMed Sci Sports (2017) 27(12):1893-901. doi:10.1111/sms.12829

56. Mohr M, Lindenskov A, Holm PM, Nielsen HP, Mortensen J, Weihe P, et al. Football training improves cardiovascular health profile in sedentary, premenopausal hypertensive women. Scand J Med Sci Sports (2014) 24 (Suppl 1):36-42. doi:10.1111/sms.12278

57. Mohr M, Helge EW, Petersen LF, Lindenskov A, Weihe P, Mortensen J, et al. Effects of soccer vs swim training on bone formation in sedentary middle-aged women. Eur J Appl Physiol (2015) 115(12):2671-9. doi:10.1007/ s00421-015-3231-8

58. de Sousa MV, Fukui R, Krustrup P, Pereira RM, Silva PR, Rodrigues AC, et al. Positive effects of football on fitness, lipid profile, and insulin resistance in Brazilian patients with type 2 diabetes. Scand J Med Sci Sports (2014) 24(Suppl 1):57-65. doi:10.1111/sms.12258

59. Libeton M, Dixon JB, Laurie C, O'Brien PE. Patient motivation for bariatric surgery: characteristics and impact on outcomes. Obes Surg (2004) 14(3):392-8. doi:10.1381/096089204322917936

60. Stroh C, Weiner R, Wolff S, Knoll C, Manger T; Obesity Surgery Working Group. Influences of gender on complication rate and outcome after Roux-en-Y gastric bypass: data analysis of more than 10,000 operations from the German Bariatric Surgery Registry. Obes Surg (2014) 24(10):1625-33. doi:10.1007/s11695-014-1252-8

61. Buchwald H, Estok R, Fahrbach K, Banel D, Sledge I. Trends in mortality in bariatric surgery: a systematic review and meta-analysis. Surgery (2007) 142(4):621-32; discussion 32-5. doi:10.1016/j.surg.2007.07.018

62. Schwartz J, Bashian C, Kushnir L, Nituica C, Slotman GJ. Variation in clinical characteristics of women versus men preoperative for laparoscopic Roux-en-Y gastric bypass: analysis of 83,059 patients. Am Surg (2017) 83(9): 947-51.

63. Stroh C, Weiner R, Wolff S, Knoll C, Manger T; Obesity Surgery Working Group and Competence Network Obesity. Are there gender-specific aspects in obesity and metabolic surgery? Data analysis from the German Bariatric Surgery Registry. Viszeralmedizin (2014) 30(2):125-32. doi:10.1159/ 000360148
64. Shah N, Greenberg JA, Leverson G, Statz AK, Jolles SA, Funk LM. Weight loss after bariatric surgery: a propensity score analysis. J Surg Res (2016) 202(2):449-54. doi:10.1016/j.jss.2016.01.041

65. Meyer SB, Thompson C, Hakendorf P, Horwood C, McNaughton D, Gray J, et al. Bariatric surgery revisions and private health insurance. Obes Res Clin Pract (2017) 11(5):616-21. doi:10.1016/j.orcp.2017.04.009

66. Coblijn UK, Karres J, de Raaff CA, de Castro SM, Lagarde SM, van Tets WF, et al. Predicting postoperative complications after bariatric surgery: the Bariatric Surgery Index for Complications, BASIC. Surg Endosc (2017) 31(11):4438-45. doi:10.1007/s00464-017-5494-0

67. Escobar-Morreale HF, Santacruz E, Luque-Ramirez M, Botella Carretero JI. Prevalence of 'obesity-associated gonadal dysfunction' in severely obese men and women and its resolution after bariatric surgery: a systematic review and meta-analysis. Hum Reprod Update (2017) 23(4):390-408. doi:10.1093/ humupd/dmx012

68. Xu H, Zhang P, Han X, Yu H, Di J, Zou J, et al. Sex effect on obesity indices and metabolic outcomes in patients with obese obstructive sleep apnea and type 2 diabetes after laparoscopic Roux-en-Y gastric bypass surgery: a preliminary study. Obes Surg (2016) 26(11):2629-39. doi:10.1007/s11695-0162140-1

69. Stroh C, Groh C, Weiner R, Ludwig K, Wolff S, Kabelitz M, et al. Are there gender-specific aspects of gastric banding? Data analysis from the quality assurance study of the surgical treatment of obesity in Germany. Obes Surg (2013) 23(11):1783-9. doi:10.1007/s11695-013-0964-5

70. Thereaux J, Lesuffleur T, Paita M, Czernichow S, Basdevant A, Msika S, et al. Long-term follow-up after bariatric surgery in a national cohort. Br J Surg (2017) 104(10):1362-71. doi:10.1002/bjs.10557

71. Kanerva N, Larsson I, Peltonen M, Lindroos AK, Carlsson LM. Sociodemographic and lifestyle factors as determinants of energy intake and macronutrient composition: a 10-year follow-up after bariatric surgery. Surg Obes Relat Dis (2017) 13(9):1572-83. doi:10.1016/j.soard.2017.05.025

72. Jamalallail AA, Winters SJ, Mokshagundam SPL, Krishnasamy SS. Gender differences in the impact of bariatric surgery on bone and mineral metabolism. Endocrine Society's 98th Annual Meeting and Expo. Boston: Endocrine Reviews (2016)

73. Wee CC, Jones DB, Apovian C, Hess DT, Chiodi SN, Bourland AC, et al. Weight loss after bariatric surgery: do clinical and behavioral factors explain racial differences? Obes Surg (2017) 27(11):2873-84. doi:10.1007/ s11695-017-2701-y

74. Elli EF, Gonzalez-Heredia R, Patel N, Masrur M, Murphey M, Chen J, et al. Bariatric surgery outcomes in ethnic minorities. Surgery (2016) 160(3): 805-12. doi:10.1016/j.surg.2016.02.023

75. Khorgami Z, Arheart KL, Zhang C, Messiah SE, de la Cruz-Munoz N. Effect of ethnicity on weight loss after bariatric surgery. Obes Surg (2015) 25(5):769-76. doi:10.1007/s11695-014-1474-9

76. Ng J, Seip R, Stone A, Ruano G, Tishler D, Papasavas P. Ethnic variation in weight loss, but not co-morbidity remission, after laparoscopic gastric banding and Roux-en-Y gastric bypass. Surg Obes Relat Dis (2015) 11(1):94-100. doi:10.1016/j.soard.2014.07.013

77. Coleman KJ, Brookey J. Gender and racial/ethnic background predict weight loss after Roux-en-Y gastric bypass independent of health and lifestyle behaviors. Obes Surg (2014) 24(10):1729-36. doi:10.1007/s11695-014-1268-0

78. Ding EL, Song Y, Malik VS, Liu S. Sex differences of endogenous sex hormones and risk of type 2 diabetes: a systematic review and meta-analysis. JAMA (2006) 295(11):1288-99. doi:10.1001/jama.295.11.1288

79. Bijlsma-Rutte A, Braamse AMJ, van Oppen P, Snoek FJ, Enzlin P, Leusink P, et al. Screening for sexual dissatisfaction among people with type 2 diabetes in primary care. J Diabetes Complications (2017) 31(11):1614-9. doi:10.1016/j. jdiacomp.2017.07.020

80. Bak E, Marcisz C, Krzeminska S, Dobrzyn-Matusiak D, Foltyn A, DrosdzolCop A. Relationships of sexual dysfunction with depression and acceptance of illness in women and men with type 2 diabetes mellitus. Int J Environ Res Public Health (2017) 14(9):E1073. doi:10.3390/ijerph14091073

81. Kim C, Dabelea D, Kalyani RR, Christophi CA, Bray GA, Pi-Sunyer X, et al. Changes in visceral adiposity, subcutaneous adiposity, and sex hormones in the diabetes prevention program. J Clin Endocrinol Metab (2017) 102(9):3381-9. doi:10.1210/jc.2017-00967

82. Esposito K, Giugliano D. Obesity, the metabolic syndrome, and sexual dysfunction. Int J Impot Res (2005) 17(5):391-8. doi:10.1038/sj.ijir.3901333 
83. Weinberg AE, Eisenberg M, Patel CJ, Chertow GM, Leppert JT. Diabetes severity, metabolic syndrome, and the risk of erectile dysfunction. J Sex Med (2013) 10(12):3102-9. doi:10.1111/jsm.12318

84. Feldman HA, Goldstein I, Hatzichristou DG, Krane RJ, McKinlay JB. Impotence and its medical and psychosocial correlates: results of the Massachusetts Male Aging Study. J Urol (1994) 151(1):54-61. doi:10.1016/S0022-5347(17) 34871-1

85. Araña Rosaínz Mde J, Ojeda MO, Acosta JR, Elías-Calles LC, González NO, Herrera OT, et al. Imbalanced low-grade inflammation and endothelial activation in patients with type 2 diabetes mellitus and erectile dysfunction. J Sex Med (2011) 8(7):2017-30. doi:10.1111/j.1743-6109.2011.02277.x

86. Kamenov ZA. A comprehensive review of erectile dysfunction in men with diabetes. Exp Clin Endocrinol Diabetes (2015) 123(3):141-58. doi:10.1055/ s-0034-1394383

87. Wang C, Jackson G, Jones TH, Matsumoto AM, Nehra A, Perelman MA, et al. Low testosterone associated with obesity and the metabolic syndrome contributes to sexual dysfunction and cardiovascular disease risk in men with type 2 diabetes. Diabetes Care (2011) 34(7):1669-75. doi:10.2337/ dc10-2339

88. Ponce OJ, Spencer-Bonilla G, Alvarez-Villalobos N, Serrano V, Singh-Ospina N, Rodriguez-Gutierrez R, et al. The efficacy and adverse events of testosterone replacement therapy in hypogonadal men: a systematic review and meta-analysis of randomized, placebo-controlled trials. JClin Endocrinol Metab (2018). doi:10.1210/jc.2018-00404

89. Anaissie J, Roberts NH, Wang P, Yafi FA. Testosterone replacement therapy and components of the metabolic syndrome. Sex Med Rev (2017) 5(2):200-10. doi:10.1016/j.sxmr.2017.01.003

90. Montorsi F, Adaikan G, Becher E, Giuliano F, Khoury S, Lue TF, et al. Summary of the recommendations on sexual dysfunctions in men.J Sex Med (2010) 7(11):3572-88. doi:10.1111/j.1743-6109.2010.02062.x

91. Wing RR, Rosen RC, Fava JL, Bahnson J, Brancati F, Gendrano Iii IN, et al. Effects of weight loss intervention on erectile function in older men with type 2 diabetes in the Look AHEAD trial. J Sex Med (2010) 7(1 Pt 1):156-65. doi:10.1111/j.1743-6109.2009.01458.x

92. Gupta BP, Murad MH, Clifton MM, Prokop L, Nehra A, Kopecky SL. The effect of lifestyle modification and cardiovascular risk factor reduction on erectile dysfunction: a systematic review and meta-analysis. Arch Intern Med (2011) 171(20):1797-803. doi:10.1001/archinternmed.2011.440

93. Minami H, Furukawa S, Sakai T, Niiya T, Miyaoka H, Miyake T, et al. Physical activity and prevalence of erectile dysfunction in Japanese patients with type 2 diabetes mellitus: the Dogo Study. J Diabetes Investig (2018) 9(1):193-8. doi:10.1111/jdi.12660

94. Cai X, Tian Y, Wu T, Cao CX, Bu SY, Wang KJ. The role of statins in erectile dysfunction: a systematic review and meta-analysis. Asian J Androl (2014) 16(3):461-6. doi:10.4103/1008-682X.123678

95. Elgendy AY, Elgendy IY, Mahmoud AN, Al-Ani M, Moussa MM, Mahmoud A, et al. Statin use in men and new onset of erectile dysfunction: a systematic review and meta-analysis. Am J Med (2018) 131(4):387-94. doi:10.1016/j. amjmed.2017.10.043

96. Hehemann MC, Kashanian JA. Can lifestyle modification affect men's erectile function? Transl Androl Urol (2016) 5(2):187-94. doi:10.21037/ tau.2016.02.05

97. Kim C, Barrett-Connor E, Aroda VR, Mather KJ, Christophi CA, Horton ES, et al. Testosterone and depressive symptoms among men in the Diabetes Prevention Program. Psychoneuroendocrinology (2016) 72:63-71. doi:10.1016/ j.psyneuen.2016.06.009

98. Same RV, Al Rifai M, Feldman DI, Billups KL, Brawner CA, Dardari ZA, et al. Prognostic value of exercise capacity among men undergoing pharmacologic treatment for erectile dysfunction: the FIT Project. Clin Cardiol (2017) 40(11):1049-54. doi:10.1002/clc.22768

99. Hackett G, Krychman M, Baldwin D, Bennett N, El-Zawahry A, Graziottin A, et al. Coronary heart disease, diabetes, and sexuality in men. J Sex Med (2016) 13(6):887-904. doi:10.1016/j.jsxm.2016.01.023

100. Janghorbani M, Mansourian M, Hosseini E. Systematic review and meta-analysis of age at menarche and risk of type 2 diabetes. Acta Diabetol (2014) 51(4):519-28. doi:10.1007/s00592-014-0579-x

101. Elks CE, Ong KK, Scott RA, van der Schouw YT, Brand JS, Wark PA, et al. Age at menarche and type 2 diabetes risk: the EPIC-InterAct study. Diabetes Care (2013) 36(11):3526-34. doi:10.2337/dc13-0446
102. Wilson DA, Derraik JG, Rowe DL, Hofman PL, Cutfield WS. Earlier menarche is associated with lower insulin sensitivity and increased adiposity in young adult women. PLoS One (2015) 10(6):e0128427. doi:10.1371/journal. pone. 0128427

103. Mueller NT, Pereira MA, Demerath EW, Dreyfus JG, MacLehose RF, Carr JJ, et al. Earlier menarche is associated with fatty liver and abdominal ectopic fat in midlife, independent of young adult BMI: the CARDIA study. Obesity (Silver Spring) (2015) 23(2):468-74. doi:10.1002/oby.20950

104. Li H, Shen L, Song L, Liu B, Zheng X, Xu S, et al. Early age at menarche and gestational diabetes mellitus risk: results from the Healthy Baby Cohort study. Diabetes Metab (2017) 43(3):248-52. doi:10.1016/j.diabet.2017.01.002

105. Ibanez L, Lopez-Bermejo A, Diaz M, Marcos MV, de Zegher F. Early metformin therapy to delay menarche and augment height in girls with precocious pubarche. Fertil Steril (2011) 95(2):727-30. doi:10.1016/j. fertnstert.2010.08.052

106. Ibanez L, Lopez-Bermejo A, Diaz M, Marcos MV, de Zegher F. Early metformin therapy (age 8-12 years) in girls with precocious pubarche to reduce hirsutism, androgen excess, and oligomenorrhea in adolescence. JClin Endocrinol Metab (2011) 96(8):E1262-7. doi:10.1210/jc.2011-0555

107. Jayasena $\mathrm{CN}$, Franks S. The management of patients with polycystic ovary syndrome. Nat Rev Endocrinol (2014) 10(10):624-36. doi:10.1038/ nrendo.2014.102

108. Lim SS, Davies MJ, Norman RJ, Moran LJ. Overweight, obesity and central obesity in women with polycystic ovary syndrome: a systematic review and meta-analysis. Hum Reprod Update (2012) 18(6):618-37. doi:10.1093/ humupd/dms030

109. Naderpoor N, Shorakae S, de Courten B, Misso ML, Moran LJ, Teede HJ. Metformin and lifestyle modification in polycystic ovary syndrome: systematic review and meta-analysis. Hum Reprod Update (2015) 21(5):560-74. doi:10.1093/humupd/dmv025

110. Unfer V, Facchinetti F, Orru B, Giordani B, Nestler J. Myo-inositol effects in women with PCOS: a meta-analysis of randomized controlled trials. Endocr Connect (2017) 6(8):647-58. doi:10.1530/EC-17-0243

111. Ferjan S, Janez A, Jensterle M. Dpp4 inhibitor sitagliptin as a potential treatment option in metformin intolerant obese women with polycystic ovary syndrome: a pilot randomized study. Endocr Pract (2018) 24(1):69-77. doi:10.4158/EP-2017-0027

112. Tzotzas T, Karras SN, Katsiki N. Glucagon-like peptide-1 (GLP-1) receptor agonists in the treatment of obese women with polycystic ovary syndrome. Curr Vasc Pharmacol (2017) 15(3):218-29. doi:10.2174/ 1570161114666161221115324

113. Harreiter J, Kautzky-Willer A. Gender obesity report - Einfluss von Adipositas auf Reproduktion und Schwangerschaft. Wien Med Wochenschr (2016) 166(3-4):129-38. doi:10.1007/s10354-015-0410-5

114. Egan AM, Vellinga A, Harreiter J, Simmons D, Desoye G, Corcoy R, et al. Epidemiology of gestational diabetes mellitus according to IADPSG/WHO 2013 criteria among obese pregnant women in Europe. Diabetologia (2017) 60(10):1913-21. doi:10.1007/s00125-017-4353-9

115. Harreiter J, Simmons D, Desoye G, Corcoy R, Adelantado JM, Devlieger R, et al. IADPSG and WHO 2013 gestational diabetes mellitus criteria identify obese women with marked insulin resistance in early pregnancy. Diabetes Care (2016) 39(7):e90-2. doi:10.2337/dc16-0200

116. Bellamy L, Casas JP, Hingorani AD, Williams D. Type 2 diabetes mellitus after gestational diabetes: a systematic review and meta-analysis. Lancet (2009) 373(9677):1773-9. doi:10.1016/S0140-6736(09)60731-5

117. Harreiter J, Dovjak G, Kautzky-Willer A. Gestational diabetes mellitus and cardiovascular risk after pregnancy. Womens Health (Lond) (2014) 10(1):91-108. doi:10.2217/WHE.13.69

118. Mauvais-Jarvis F, Manson JE, Stevenson JC, Fonseca VA. Menopausal hormone therapy and type 2 diabetes prevention: evidence, mechanisms, and clinical implications. Endocr Rev (2017) 38(3):173-88. doi:10.1210/er. 2016-1146

119. Sanabria-Martinez G, Garcia-Hermoso A, Poyatos-Leon R, Alvarez-Bueno C, Sanchez-Lopez M, Martinez-Vizcaino V. Effectiveness of physical activity interventions on preventing gestational diabetes mellitus and excessive maternal weight gain: a meta-analysis. BJOG (2015) 122(9):1167-74. doi:10.1111/ 1471-0528.13429

120. Bain E, Crane M, Tieu J, Han S, Crowther CA, Middleton P. Diet and exercise interventions for preventing gestational diabetes mellitus. 
Cochrane Database Syst Rev (2015) 4:CD010443. doi:10.1002/14651858. CD010443.pub2

121. Quinlivan JA, Lam LT, Fisher J. A randomised trial of a four-step multidisciplinary approach to the antenatal care of obese pregnant women. Aust N Z J Obstet Gynaecol (2011) 51(2):141-6. doi:10.1111/j.1479-828X.2010. 01268.x

122. Dodd JM, Turnbull D, McPhee AJ, Deussen AR, Grivell RM, Yelland LN, et al. Antenatal lifestyle advice for women who are overweight or obese: LIMIT randomised trial. BMJ (2014) 348:g1285. doi:10.1136/bmj.g1285

123. Poston L, Bell R, Croker H, Flynn AC, Godfrey KM, Goff L, et al. Effect of a behavioural intervention in obese pregnant women (the UPBEAT study): a multicentre, randomised controlled trial. Lancet Diabetes Endocrinol (2015) 3(10):767-77. doi:10.1016/S2213-8587(15)00227-2

124. Koivusalo SB, Rono K, Klemetti MM, Roine RP, Lindstrom J, Erkkola M, et al. Gestational diabetes mellitus can be prevented by lifestyle intervention: the Finnish Gestational Diabetes Prevention Study (RADIEL): a randomized controlled trial. Diabetes Care (2016) 39(1):24-30. doi:10.2337/ dc15-0511

125. Simmons D, Jelsma JG, Galjaard S, Devlieger R, van Assche A, Jans G, et al. Results from a European multicenter randomized trial of physical activity and/or healthy eating to reduce the risk of gestational diabetes mellitus: the DALI lifestyle pilot. Diabetes Care (2015) 38(9):1650-6. doi:10.2337/ dc15-0360

126. Simmons D, Devlieger R, van Assche A, Jans G, Galjaard S, Corcoy R, et al. Effect of physical activity and/or healthy eating on GDM risk: the DALI Lifestyle Study. J Clin Endocrinol Metab (2017) 102(3):903-13. doi:10.1210/ jc.2016-3455

127. Syngelaki A, Nicolaides KH, Balani J, Hyer S, Akolekar R, Kotecha R, et al. Metformin versus placebo in obese pregnant women without diabetes mellitus. N Engl J Med (2016) 374(5):434-43. doi:10.1056/NEJMoa1509819

128. Chiswick C, Reynolds RM, Denison F, Drake AJ, Forbes S, Newby DE, et al. Effect of metformin on maternal and fetal outcomes in obese pregnant women (EMPOWaR): a randomised, double-blind, placebo-controlled trial. Lancet Diabetes Endocrinol (2015) 3(10):778-86. doi:10.1016/S22138587(15)00219-3
129. Aroda VR, Christophi CA, Edelstein SL, Zhang P, Herman WH, BarrettConnor E, et al. The effect of lifestyle intervention and metformin on preventing or delaying diabetes among women with and without gestational diabetes: the Diabetes Prevention Program outcomes study 10-year follow-up. J Clin Endocrinol Metab (2015) 100(4):1646-53. doi:10.1210/jc. 2014-3761

130. Simmons D, van Poppel MN. UPBEAT, RADIEL, and DALI: what's the difference? Lancet Diabetes Endocrinol (2015) 3(10):761. doi:10.1016/S22138587(15)00318-6

131. Agha-Jaffar R, Oliver N, Johnston D, Robinson S. Gestational diabetes mellitus: does an effective prevention strategy exist? Nat Rev Endocrinol (2016) 12(9):533-46. doi:10.1038/nrendo.2016.88

132. Tobias DK, Zhang C, van Dam RM, Bowers K, Hu FB. Physical activity before and during pregnancy and risk of gestational diabetes mellitus: a metaanalysis. Diabetes Care (2011) 34(1):223-9. doi:10.2337/dc10-1368

133. Stentz NC, Koelper N, Sammel MD, Barnhart KT, Nicolais OL, Senapati S. Infertility \& mortality. 73rd Scientific Congress and Expo of the American-Societyfor-Reproductive-Medicine (ASRM). San Antonio, TX: Fertil Steril (2017). e4 p.

134. LeBlanc ES, Kapphahn K, Hedlin H, Desai M, Parikh NI, Liu S, et al. Reproductive history and risk of type 2 diabetes mellitus in postmenopausal women: findings from the Women's Health Initiative. Menopause (2017) 24(1):64-72. doi:10.1097/GME.0000000000000714

Conflict of Interest Statement: The authors declare that the research was conducted in the absence of any commercial or financial relationships that could be construed as a potential conflict of interest.

Copyright (c) 2018 Harreiter and Kautzky-Willer. This is an open-access article distributed under the terms of the Creative Commons Attribution License (CC BY). The use, distribution or reproduction in other forums is permitted, provided the original author(s) and the copyright owner are credited and that the original publication in this journal is cited, in accordance with accepted academic practice. No use, distribution or reproduction is permitted which does not comply with these terms. 